\title{
REPRESENTAÇõES COMPARTILHADAS SOBRE O PROGRAMA MINHA CASA MINHA VIDA: ANÁLISE DO DISCURSO SOBRE A CONSTRUÇÃO DO NOVO TEMPO NA CIDADE DE LAJEADO ${ }^{12}$
}

\author{
DOROTHÉE SY
}

\begin{abstract}
RESUMO
0 objetivo deste artigo é compreender como são construídas as representações sociais sobre o Programa Minha Casa Minha Vida, 0 maior programa de habitações de interesse social instaurado em 2009, identificando os atores envolvidos na construção da ideia do "sonho da casa própria" e mostrando o modo como as imagens dialogam de maneira complexa com os discursos institucionais e midiáticos. Neste sentido, busca-se dialogar com as imagens (discursos) institucionais dos conjuntos habitacionais na cidade de Lajeado, uma cidade de médio porte do Rio Grande do Sul, obtidas por meio de pesquisa na internet em sites institucionais e de jornais de circulação regional. 0 referencial teórico utilizado são os autores abordados que problematizam as relações sobre 0 estado e o discurso como Burke, Foucault, Hall, Olson e outros. A solução dos gigantescos conjuntos habitacionais construídos nas periferias das cidades brasileiras para driblar a crise habitacional se torna um símbolo de progresso e de modernidade e, em certos casos, a "salvação" de um Estado caritativo para a população de baixa renda. As imagens elaboradas pela imprensa associadas aos discursos institucionais representam diferentes formas de discurso sobre as políticas públicas de habitação de interesse social em um contexto de vulnerabilidade e precarização das condições de vida dos sujeitos.
\end{abstract}

\section{PALAVRAS-CHAVE}

Representações; Habitação de interesse social; Programa Minha Casa Minha Vida.

\section{LES REPRÉSENTATIONS PARTAGÉES LIÉES AU PROGRAMME MINHA CASA MINHA VIDA: UNE ANALYSE DU DISCOURS SUR LA CONSTRUCTION DU NOVO TEMPO DANS LA VILLE DE LAJEADO}

\begin{abstract}
RÉSUMÉ
L'objectif de cet article est de comprendre comment se construisent les représentations sociales du programme Minha Casa Minha Vida, le plus grand programme de logement social initié en 2009, en identifiant les acteurs impliqués dans la construction de l'idée du " rêve d'accession à la propriété " et montrer comment les images interagissent de manière complexe avec les discours institutionnels et médiatiques. Dans ce sens, nous cherchons à dialoguer avec les images (discours) institutionnelles des ensembles résidentiels de la ville de Lajeado, une ville moyenne du Rio Grande do Sul, obtenues par une recherche sur Internet sur des sites institutionnels et des journaux régionaux. Le référentiel théorique utilisé sont les auteurs qui problématisent
\end{abstract}

\footnotetext{
${ }^{1}$ Este artigo é fruto de um capítulo de uma dissertação de mestrado apresentada em setembro 2018 ao PROPUR - Programa de Pós-Graduação em Planejamento urbano e Regional da Universidade Federal do Rio Grande do Sul orientada pelo Prof. Dr. Carlos Ribeiro Furtado.

${ }^{2}$ Agradeço os comentários dos pareceristas anônimos que contribuíram para a redação final deste artigo, suas sugestões foram acrescentadas na medida do possível.
} 
les relations entre l'état et le discours comme Burke, Foucault, Hall, Olson et autres. La solution des complexes résidentiels gigantesques construits dans les périphéries des villes brésiliennes pour surmonter la crise du logement devient un symbole de progrès et de modernité et, dans certains cas, le "salut» d'un État charitable pour la population à faible revenu. Les images de presse associées aux discours institutionnels représentent différentes formes de discours sur les politiques publiques de logement d'intérêt social dans un contexte de vulnérabilité et de précarité des conditions de vie des sujets.

\title{
MOTS-CLÉS
}

Représentations; Logement social; Programa Minha Casa Minha Vida.

\author{
Shared Representations of the Minha Casa Minha Vida Program: an \\ ANALYSIS OF THE DISCOURSE ON THE CONSTRUCTION OF THE NOVO TEMPO IN THE \\ CITY OF LAJEADO
}

\begin{abstract}
The aim of this article is to understand how the social representations of the Minha Casa Minha Vida program, the largest social housing program initiated in 2009, are constructed by identifying the actors involved in constructing the idea of the dream of Home Ownership and show how images interact in complex ways with institutional and media discourses. In this sense, we seek to dialogue with the institutional (logical) images of the residential complexes of the city of Lajeado, an average city of Rio Grande do Sul, obtained through an Internet search on institutional sites and regional newspapers. The theoretical reference used are the authors who problematize the relations on the state and the discourse like Burke, Foucault, Hall, Olson and others. The solution of the gigantic residential complexes built in the outskirts of Brazilian cities to overcome the housing crisis becomes a symbol of progress and modernity and, in some cases, the "salvation" of a charitable state for the low-income population. Press images associated with institutional discourses represent different forms of discourse on pubic housing policies of social interest in a context of vulnerability and precarious living conditions of subjects.
\end{abstract}

\section{KEY-WORDS}

Representations; Social housing; Minha Casa Minha Vida Program.

\section{REPRESENTACIONES COMPARTIDAS SOBRE EL PROGRAMA MINHA CASA MINHA VIDA: ANÁLISIS DEL DISCURSO SOBRE LA CONSTRUCCIÓN DEL NOVO TEMPO EN LA CIUDAD DE LAJEADO}

\begin{abstract}
RESUMEN
El objetivo de este artículo es comprender cómo se construyen las representaciones sociales sobre el Programa Minha Casa Minha Vida, el mayor programa de viviendas de interés social instaurado en 2009, identificando a los actores involucrados en la construcción de la idea del "sueño de la casa propia" mostrando el modo en que las imágenes dialogan de manera compleja con los discursos institucionales y mediáticos. En este sentido, se busca dialogar con las imágenes (discursos) institucionales de los conjuntos habitacionales en la ciudad de Lajeado, una ciudad de mediano porte de Rio Grande do Sul, obtenidas por medio de investigación en internet en sitios institucionales y de diarios de circulación regional. El referencial teórico utilizado son los autores que problematizan las relaciones sobre el estado y el discurso como Burke, Foucault, Hall, Olson y otros. La solución
\end{abstract}


de los gigantescos conjuntos habitacionales construidos en las periferias de las ciudades brasileñas para driblar la crisis habitacional se convierte en un símbolo de progreso y de modernidad y, en ciertos casos, la "salvación" de un Estado caritativo para la población de bajos ingresos. Las imágenes elaboradas por la prensa asociadas a los discursos institucionales representan diferentes formas de discurso sobre las políticas públicas de vivienda de interés social en un contexto de vulnerabilidad y precarización de las condiciones de vida de los sujetos.

\section{PALABRAS CLAVE}

Representaciones; Vivienda de interés social; Minha Casa Minha Vida. 


\section{INTRODUÇÃO}

As representações urbanas são construídas e usadas por diferentes agentes para justificar os discursos específicos sobre a cidade (urbanístico, político, publicitário, jornalístico, etc.). O estado se apresenta como um dos agentes mais influentes no ordenamento e planejamento do espaço urbano. As relações entre o Poder Público e a habitação de interesse social, que se concretizam através das políticas públicas de habitação social, se expressam como um jogo complexo de combinações, representações e saberes, com lugares definidos dentro de relações elaboradas na sociedade onde participam diversos atores.

Por meio do estudo das teorias ligadas ao conceito de representação, este trabalho tenta desvendar os mecanismos de construção discursiva da habitação de interesse social, buscando captar os fundamentos ideológicos das representações visuais e discursivas ligadas ao Programa Minha Casa Minha Vida (PMCMV). Implementado pelo Governo Federal em 2009 por meio da lei $n^{\circ} 11.977$, o programa tem o objetivo de "criar mecanismos de incentivo à produção e aquisição de novas unidades habitacionais ou requalificação de imóveis urbanos e produção ou reforma de habitações rurais, para famílias com renda mensal de até R\$ 4.650,00" (BRASIL, 2009). O PMCMV, maior programa habitacional do Brasil, desde a criação do BNH (Banco Nacional de Habitação) em 1964, tem tido como resultados conjuntos habitacionais localizados em áreas periféricas isoladas e distantes dos setores de comércio e serviços. Muitas vezes, estão localizados em áreas rurais onde há disponibilidade de terra a preços mais baixos e, em geral, sem fácil acesso ao transporte público e equipamentos de educação, saúde e lazer. A baixa qualidade urbanística do entorno dos conjuntos habitacionais, associada aos modelos de construção repetitivos "relega a inserção urbana dos empreendimentos a uma questão de relevância secundária, senão inexistentes"(ROLNIK et al., 2015) e favorece os interesses da indústria da construção civil: empreiteiras de construção e agentes de mercado imobiliário. No entanto a escolha da localização não ocorre aleatoriamente e obedece a uma lógica relacionada com a natureza das políticas habitacionais, e com os interesses dos diferentes agentes envolvidos na produção dos conjuntos habitacionais. Além disso, "a disponibilidade e os preços dos terrenos também exercem papel fundamental nas escolhas locacionais"(SILVA; TOURINHO, 2015, p.404)3.

O artigo apresenta o marco teórico e dialoga com teorias sobre as representações sociais, tentando entender as representações produzidas dentro de um cenário polifônico

\footnotetext{
${ }^{3}$ Diversos estudos têm sido publicados sobre o programa MCMV, em minha dissertação discuto vários autores que abordam as problemáticas ligadas ao programa. Para maiores detalhes ver SY, 2018 especialmente as páginas 28-30 e p.104-107.
} 
onde diferentes atores disputam o poder dentro de contextos sócio-políticos locais que dialogam com problemáticas nacionais mais amplas.

\title{
REPRESENTAÇÕES
}

A ideia de trabalhar com as representações se relaciona com problemáticas encontradas ao longo de minha pesquisa sobre a construção dos conjuntos habitacionais Novo Tempo I e II no município de Lajeado ${ }^{4}$. O próprio nome atribuído ao conjunto já denota uma ruptura na continuidade da vida das famílias, pois aderindo ao PMCMV elas estariam simbolicamente entrando em um "novo tempo" em suas próprias vidas. Mais tarde, pesquisando na imprensa local e nos discursos dos atores institucionais como representantes do poder público municipal e a própria publicidade veiculada pela prefeitura na divulgação do projeto, comecei a pensar na relevância de entender a construção desses discursos e analisar como são elaborados. Neste sentido, a bibliografia trabalhada ao longo do curso foi de grande valia e contribuiu para colocar em destaque as construções discursivas que definiam um determinado lugar social tanto dos atores institucionais quanto dos "beneficiados" pelo programa.

As representações sociais são um tema clássico na sociologia. Na escola francesa os trabalhos pioneiros de Émile Durkheim e Marcel Mauss abordavam o tema das representações coletivas (ou sistemas de representação) como forma de atribuição de sentido ao mundo social. No Dictionnaire de l'ethnologie et de l'anthropologie, os autores Bonte e Izard definem sistema de representação:

\begin{abstract}
"A expressão "sistema de representação" significa geralmente os conjuntos de ideias e valores de uma sociedade [...] Toda sociedade desenvolve vários sistemas de representações especializadas: do cosmos, da totalidade social, da magia e feitiçaria, etc. Na mente dos indivíduos, estes sistemas estão presentes apenas como geralmente incompletos e parcialmente conscientes. Falamos de "representações coletivas" que demonstram atitudes intelectuais do grupo e não disposição mental individual [...] Esses fatos culturais não são simplesmente justapostos, eles formam sistemas. Assim, as classificações das espécies naturais e grupos sociais, a organização simbólica do espaço e representações do corpo são concebidas como partes interrelacionadas de uma representação cultural do mundo" (BONTE; IZARD, 1991, p. 626, tradução livre). ${ }^{5}$
\end{abstract}

\footnotetext{
${ }^{4}$ Situada a $130 \mathrm{Km}$ de Porto Alegre no Rio Grande do Sul, Lajeado pode ser considerada como uma cidade de médio porte. $O$ caso estudado representa o maior empreendimento social habitacional da cidade, ao todo 28 prédios compõem os conjuntos habitacionais Novo Tempo I e II, contendo 16 apartamentos cada, situados na faixa de renda 1, a mais baixa do programa governamental MCMV. Nessa categoria são acolhidas 498 famílias com renda mensal de até $\mathrm{R} \$ 1.600,00$.

${ }^{5}$ L'expression "système de représentation" désigne d'une manière générale les ensembles d'idées et de valeurs propres à une société [...] Toute société élaborerait ainsi plusieurs systèmes de représentations 167
} 
Se considerarmos a habitação ou o problema habitacional como um fato social total, no sentido em que ele envolve toda a vida das pessoas em sociedade, o acesso à moradia se torna um tema central nas representações sociais e na construção discursiva. Como afirma Pesavento (2008), as representações não existem, não fazem sentido fora do contexto e da sociedade na qual elas operam. Deste modo, podemos afirmar que as representações são construídas dentro de processos sociais complexos em que entram em jogo questões ligadas aos contextos culturais nos quais os indivíduos atuam e as relações de poder presentes tanto na produção dos discursos quanto em seus lugares de enunciação.

Partindo da teoria de Saussure, o fundador da ciência dos signos, a semiótica que conceitua a relação entre o significante, o significado e o signo, Hall (1997) introduz a noção de cultura e explica a relevância do contexto histórico e cultural. A representação é o resultado de um sistema de convenções sociais específicas para cada sociedade e para momentos históricos específicos. Em toda representação, o seja um produto ou uma fabricação, a realidade do mundo não pode ser considerada como transparente, como reflexo do real, mas sim deve ser interpretada. Nas palavras da historiadora Pesavento:

"Mas falemos de história, historicizemos os conceitos, porque sem dúvida há uma temporalidade na história das representações. Sendo o imaginário representações, e a representação uma imagem que quer dizer uma coisa, ela tem um sentido referente a um contexto dado, que é preciso decifrar. A elaboração de ideias-imagens de representação coletiva se constrói a partir de uma vivência ao mesmo tempo social e cultural, e tais definições determinam, ou pelo menos condicionam, o que se vê ou se faz" (PESAVENTO, 2008, p. 36).

Interpretar significa decodificar uma mensagem não intencional e não explícita e necessita a manipulação de códigos e quadros conceituais inseridos nos sistemas de valores da sociedade (HALL, 1997).

\section{InTERPRETAÇÃO DAS IMAGENS dO PROGRAMA MINHA CASA Minha VIdA}

O historiador Peter Burke (2004) lembra que as imagens, sendo evidências visuais de visões contemporâneas do mundo social, precisam estar pensadas no seu contexto social cultural e político geral. Elas performam uma variedade de funções religiosas, estéticas, políticas, etc. e muitas vezes "desenvolvem um papel específico na construção social da sociedade" (BURKE, 2004, p. 178). Seguindo o conceito de mito elaborado por Barthes, este trabalho tenta desvendar "o discurso mítico" e a mensagem oculta por trás da fabricação do sonho da casa própria veiculado pelo PMCMV, através da análise de uma série de imagens,

spécialisées : du cosmos, de la totalité sociale, de la magie et de la sorcellerie, etc. Dans l'esprit des individus, de tels systèmes ne sont présents que de façon généralement incomplet et partiellement consciente. On parlera de "représentations collectives", qui témoignent d'attitudes intellectuelles du groupe et non de dispositions mentales individuelles [...] Ces faits culturels ne sont pas simplement juxtaposés, ils forment des systèmes. Ainsi, les classifications des espèces naturelles et des groupes sociaux, l'organisation symbolique de l'espace et les représentations du corps sont conçues comme les éléments interdépendants d'une représentation culturelle du monde. 
que são testemunhos mais confiáveis do que as imagens individuais (BURKE, 2004).

A escolha da análise das imagens publicitárias oficiais do Programa Minha Casa Minha Vida se justifica por transmitir uma mensagem clara e intencional (BARTHES, 1964). A imagem transmite símbolos e a resposta do leitor a essa mensagem pode ser influenciada ou manipulada pelo texto. Nesse caso, o texto e imagem estão em uma relação complementar e a unidade da mensagem é operada a um "nível superior".

Fig. No 1: Publicidade oficial do programa Minha Casa Minha Vida

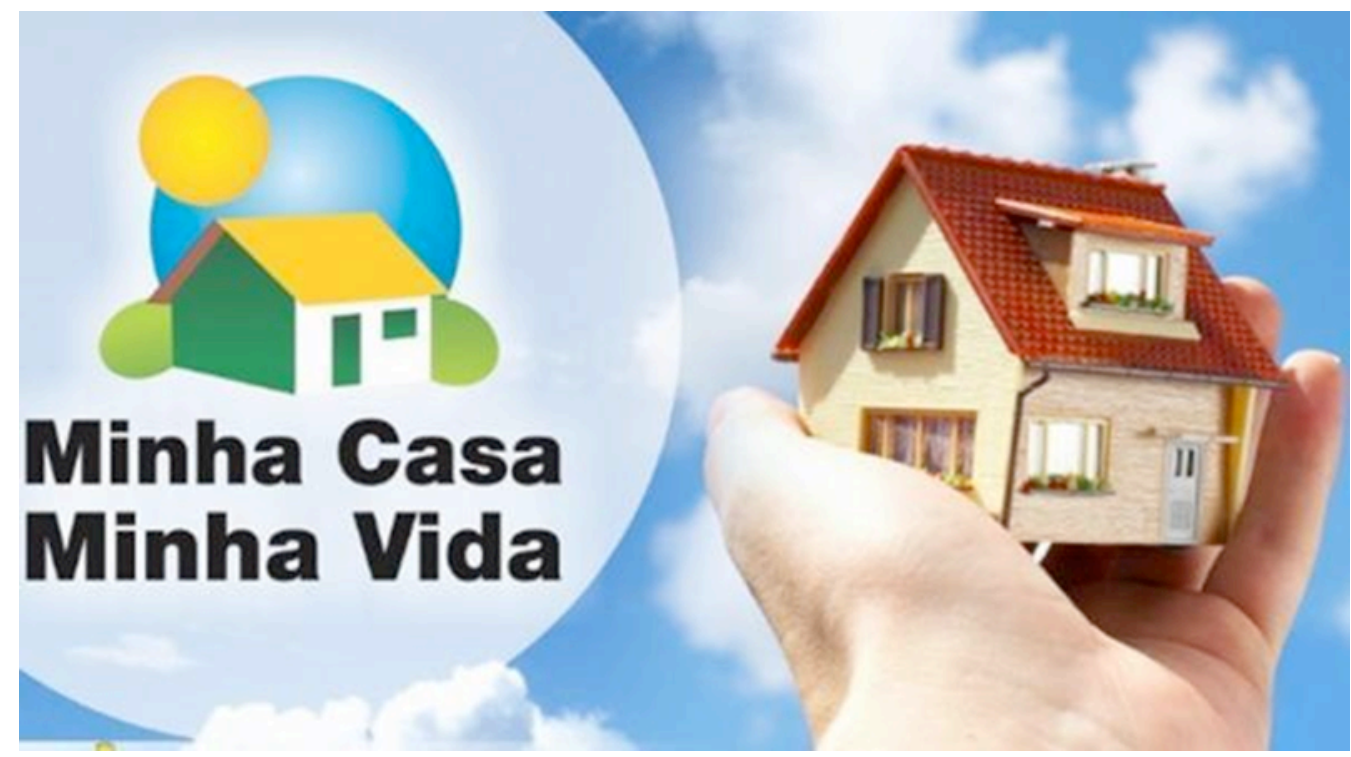

Fonte: Minha casa minha vida (2017).

Fig. Nº 2: Publicidade oficial do programa Minha Casa Minha Vida

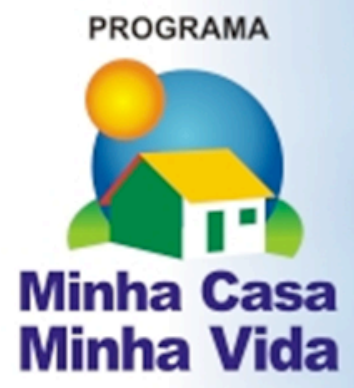

\section{Esta é a sua chance de realizar o sonho da GASA PRÓPRIA.}

SAIBA AQUI COMO PARTICIPAR

Fonte: Minha casa minha vida (2017). 
A Figura 1 apresenta uma mão estendida diante de um fundo de céu azul aberto, segurando uma casa miniatura ao lado do logo do PMCMV. A mão do estado está providenciando uma casa para seus sujeitos. Na Figura 2, no lugar da mão pode-se ler um texto destacado em um céu azul, como um texto em branco e relevo no fundo azul que se endereça pessoalmente ao interessado. Essas fotos ilustram o conceito da retórica da imagem de Barthes (1964). Ao aprofundar um pouco mais a análise, entende-se que a saída providencial para uma outra condição de vida é a ideia da propriedade privada aplicada ao setor de habitação de interesse social.

A sugestão da oferta de uma nova vida, um novo tempo, está legível no campo lexical quase místico formulado pela imprensa. Os moradores são designados como "contemplados, beneficiários, sorteados", vitoriosos que "conseguiram ganhar, alcançar, conquistar o próprio lar". As palavras: sonho, felicidade, mudança, esperança, sorte, bênção, nova vida são evocadoras de um Novo Tempo prometido pela prefeitura, em oposição ao vocabulário binário da obscuridade das condições de vida precárias dos velhos tempos. Nas Figuras 3 e 4 aparecem "beneficiários" que levam os braços ao céu em sinal de agradecimento e de alegria plena e são acompanhadas dos comentários: "escolher um apartamento é o de menos; ter a casa própria é uma benção", "hoje é meu dia de sorte!" e "escolhi o apartamento 104 do bloco 8, no Novo Tempo I". Através dessa narrativa textual e visual a mensagem transmitida é a de que mais do que uma mudança de endereço, se trata de uma mudança de vida oferecida pelo Estado.

Fig. № 3: Dia de sorteio dos apartamentos do Novo Tempo em Lajeado

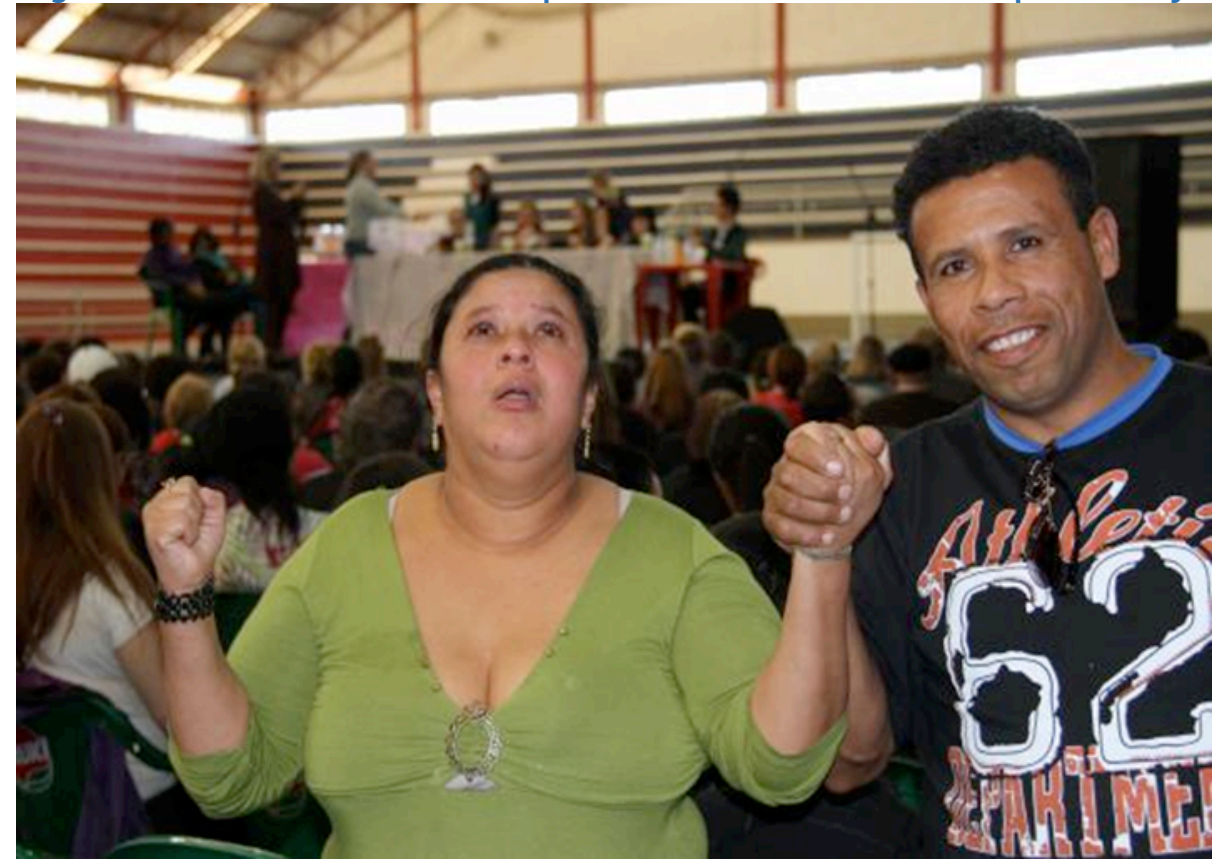

Fonte: Sorteio (2015). Jornal O Informativo do Vale. 28.06.2015 
Fig. $n^{0}$ 4: Escolha dos apartamentos pelos futuros moradores do Novo Tempo

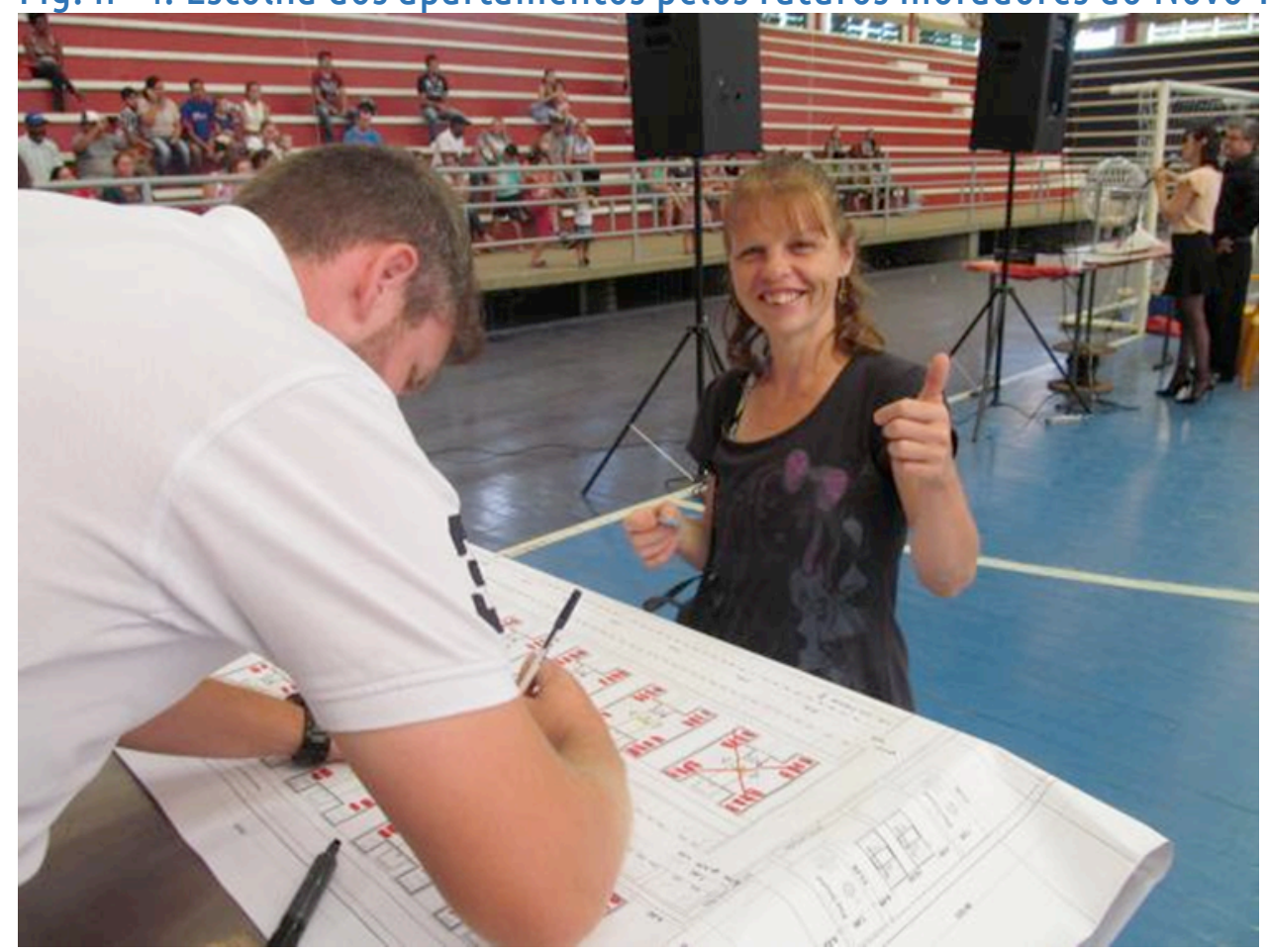

Fonte: Presser (2017). Jornal O informativo do Vale. 13.01.2017

\section{REPRESENTAÇÃO E PODER}

Baseando-se nos estudos pioneiros e fundamentais de Foucault, Marin (2005) explica que as representações estão intimamente ligadas ao poder, assim a representação tem o duplo poder de tornar imaginariamente presente e legitimar a autoridade do poder. O poder e a representação possuem uma mesma natureza, um se torna o veículo do outro: a própria representação é poder e, por conseguinte, representações visuais, ritualísticas e textuais servem o poder estabelecido. Neste sentido, existe um jogo duplo em que o estado cria representações que têm como efeito reproduzir e consolidar seu poder.

A partir de Foucault (1971), a verdade histórica e científica é contestada. O poder abrange os mecanismos específicos que são reconhecidos por induzir os comportamentos ou os discursos. Eles são, em qualquer caso, mais sutis e, especificamente, menos visíveis do que o poder político. A lei exerce controle sobre os indivíduos de fora, a norma a partir do interior. Os termos de poder e conhecimento são insidiosamente relacionados, porque o exercício desses poderes é essencialmente baseado nos conhecimentos. O saber/conhecimento abrange todos os métodos e conteúdos que são considerados aceitáveis em um tempo e em uma área definida. 
Assim, todo significado é uma manifestação da luta pelo poder. Mesmo se o poder parece invisível, ele está em todas as formas de conhecimentos que contribuem para a fabricação de nossa concepção do mundo. Conforme Olson,

"criar representações não é apenas registrar discursos ou elaborar recursos mnemônicos: é construir artefatos visíveis dotados de autonomia em relação aos autores e com propriedades especiais para controlar sua interpretação. [...] Não há representação sem intenção e interpretação" (OLSON, 1997, p. 212-213).

\section{O DISCURSO COMO CONSTRUÇÃO DA VERDADE}

No espaço urbano, as políticas públicas de habitação devem ser aprovadas com base no discurso político que produz uma verdade ou uma representação do espaço urbano: uma imagem da cidade ou de alguns bairros e regiões vai servir para justificar certas ações e políticas públicas (VILLAÇA, 1998). Com o discurso político constituindo a ação privilegiada dos poderes públicos, as classes dominantes irão se apropriar da linguagem política e do domínio de símbolos para construir uma realidade através de seus discursos. Em sua obra Linguagem e poder simbólico, o sociólogo Pierre Bourdieu explica:

O campo político é, de fato, entre outras coisas, o lugar por excelência onde os agentes buscam formar e transformar visões do mundo e atuar assim sobre o próprio mundo: o lugar por excelência onde palavras são ações e se trata do caráter simbólico do poder. Por meio da produção de slogans, programas e todos os tipos de dispositivos midiáticos, os agentes do campo político estão envolvidos em um trabalho de representação permanente através do qual eles procuram construir e impor uma visão particular do mundo social, procurando mobilizar o apoio daqueles em que, em última instância, o seu poder repousa (BOURDIEU, 2002, p. 44, tradução livre). ${ }^{6}$

No entanto, os discursos não possuem poder fora dos lugares onde são enunciados, ou seja, desligados dos contextos e atores através dos quais são produzidos (BOURDIEU, 2002). O discurso político ganha significado e eficácia unicamente no que diz respeito a certas regras e se operado em um contexto específico. Para ser legítimo, o discurso deve ser enunciado nas formas sintáticas e fonéticas legítimas, ser feito pela pessoa legitimada reconhecida como capacitada e capaz de produzir esse tipo de discurso, deve ser pronunciado numa posição legítima, ou seja, antes dos receptores legítimos e, além disso, deve ser enunciado em um contexto em que os interlocutores acreditem e confirmem o poder do enunciador. Foucault destaca a posição central do discurso na luta pelo poder: "o

\footnotetext{
${ }^{6}$ Le champs politique est en effet entre autres choses le lieu par excellence où les agents cherchent à former et à transformer les visions du monde et à agir par là sur ce monde lui même : le lieu par excellence ou les mots sont des actions et ou il en va du caractère symbolique du pouvoir. A travers la production de slogans, de programmes et de toutes sortes de relais médiatiques, les agents du champs politique sont engagés en permanence dans un travail de représentation par lequel ils entendent construire et imposer une vision particulière du monde social tout en cherchant à mobiliser le soutien de ceux sur qui, en ultime instance, leur pouvoir repose.
} 
discurso não é simplesmente o reflexo das lutas ou sistemas de dominação, mas o para quê, o porquê lutamos, o poder que queremos conquistar (FOUCAULT, 1971, p. 12, tradução livre $)^{7}$. Assim, como dito acima, os discursos possuem o sentido de reafirmar as posições sociais dos atores, consolidando lugares sociais e consolidando posições desiguais de distribuição do poder dentro da sociedade.

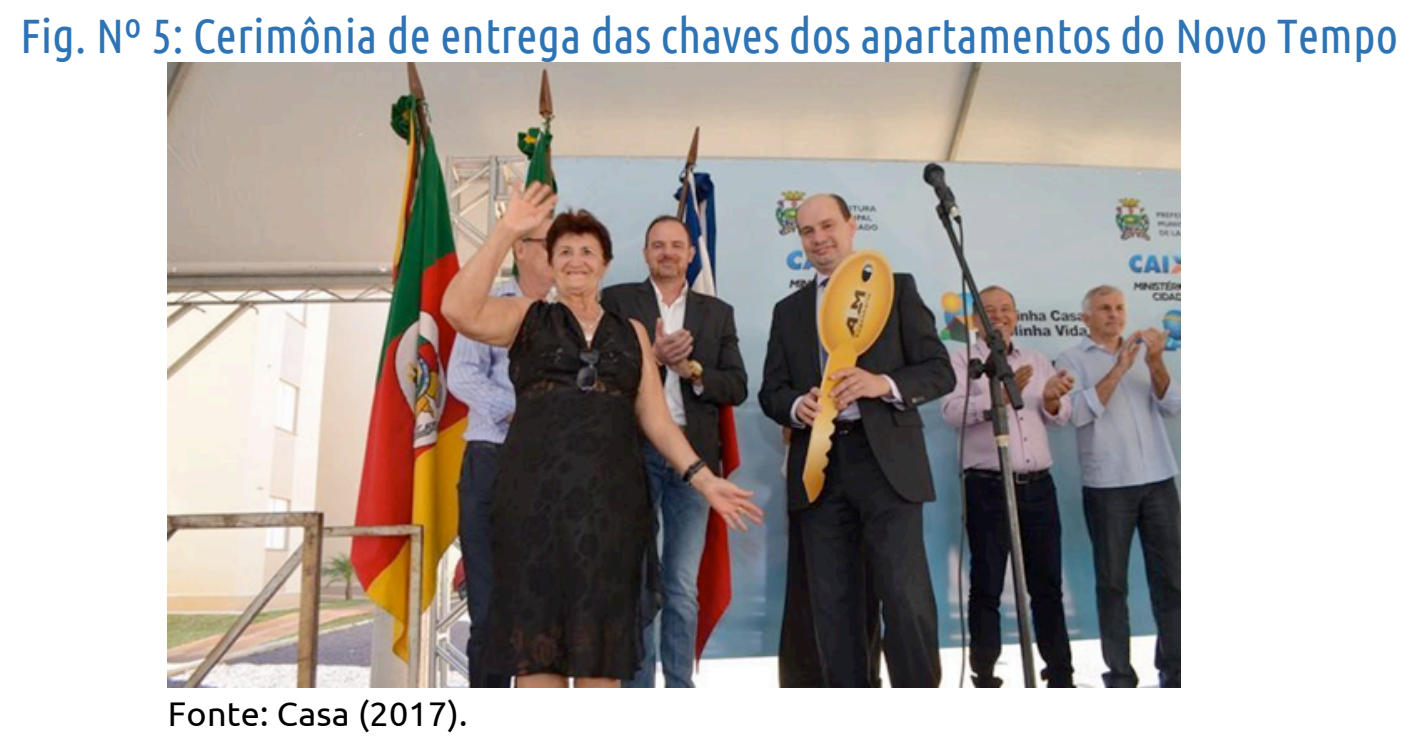

A Figura 5, imagem da cerimônia de inauguração dos conjuntos habitacionais Novo Tempo em Lajeado, em março de 2017, divulgada no jornal local e no site da prefeitura, se apresenta como altamente simbólica, pois todos os elementos do poder público estão presente. Como afirma Bourdieu (2002), o discurso é legitimado pela presença dos representantes do estado: neste caso as bandeiras, o fundo do céu azul da realização do "sonho da casa própria" (FIGURA 1) e a chave estampada com as iniciais da construtora. Essa fotografia ilustra o conceito da linguagem legítima de Bourdieu. Em uma análise mais aprofundada, pode-se entender que os agentes legítimos representantes do Estado aparecem na imagem como concedendo um benefício à população de baixa renda através da concessão simbólica das chaves do "Novo Tempo". Todo esse aparato associado às bandeiras municipal, estadual e nacional e o próprio palanque onde estão as autoridades transforma o local de enunciação em um local simbólico (FIGURA 6): o palco onde esses atores estão presentes e onde os novos moradores sobem um a um, de forma transitória, tendo apenas o direito a agradecer e manifestar sua reverência frente aos políticos e atores institucionais que concedem o benefício (FIGURA 5). Esse cerimonial coloca em evidência as relações

\footnotetext{
${ }^{7}$ Le discours n'est pas simplement ce qui traduit les luttes ou les systèmes de domination, mais ce pour quoi, ce par quoi on lutte, le pouvoir dont on cherche à s'emparer. 173
} 
desiguais de poder na sociedade.

Fig. Nº 6: Cerimônia de entrega das chaves dos apartamentos do Novo Tempo

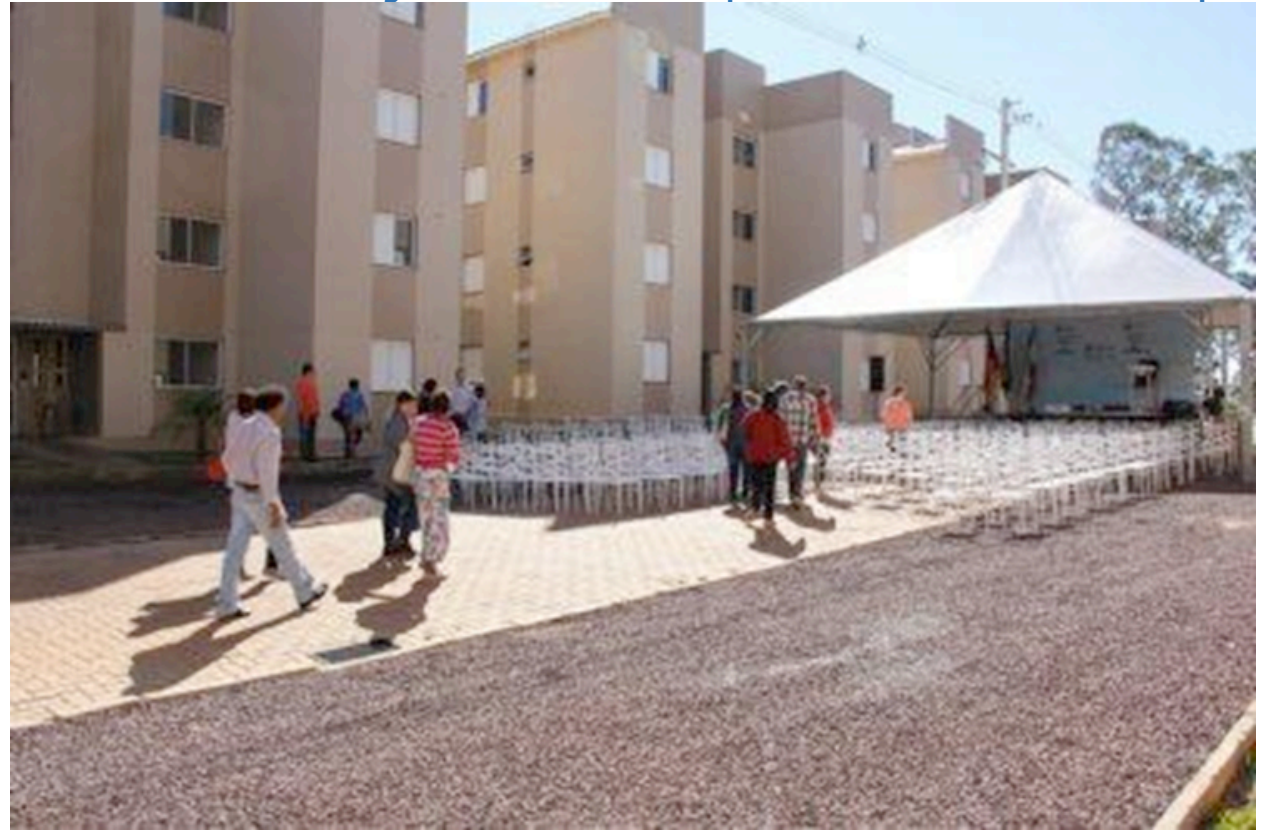

Fonte: Apartamentos (2017).

Fig. № 7: Cerimônia de entrega das chaves dos apartamentos do Novo Tempo

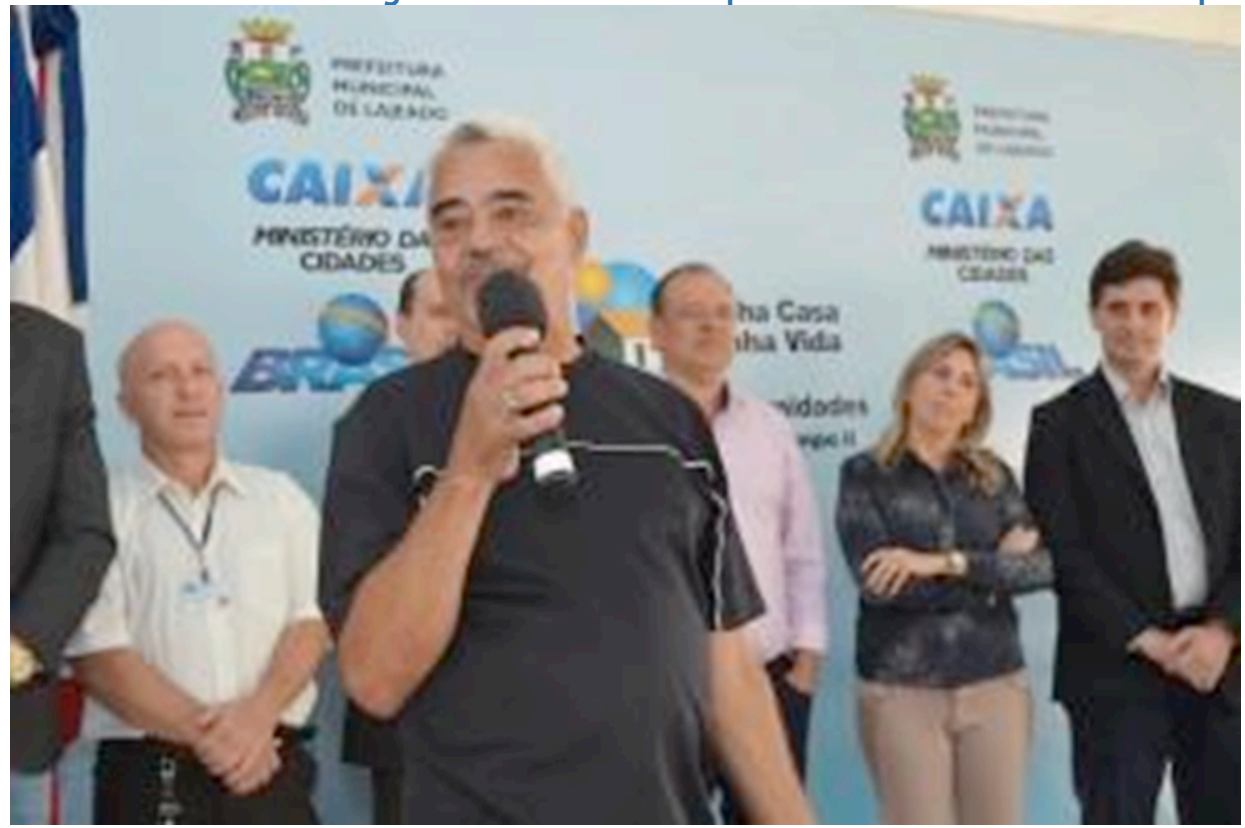

Fonte: Casa (2017). Jornal A Hora. 15.05.2017

Pode-se analisar também a visão da mídia e da prefeitura em relação aos moradores. Uma das autoridades presentes no palco ressaltou a honra de estar presente "em um momento tão importante para as famílias, um dia importante que sempre será lembrado na vida de vocês" e elogiou os moradores, dizendo que são "organizados, pacientes e se empenharam bastante". Um dos moradores (FIGURA 7) fala em nome de todos para 

agradecer e comanda: "Vamos ser felizes aqui, tá bom?".

Vários cursos oferecidos pelos Serviços de Assistência Social do município, ensinam como viver em condomínio. Isso ilustra a noção da habitação como elemento na formação ideológica, política e moral do trabalhador (BONDUKI, 1998) e o esforço de moralização por meio da habitação e da imposição do modelo de família como os dois instrumentos ativos e potente de controle das massas.

Fig. No 8: Os conjuntos habitacionais Novo Tempo I e II

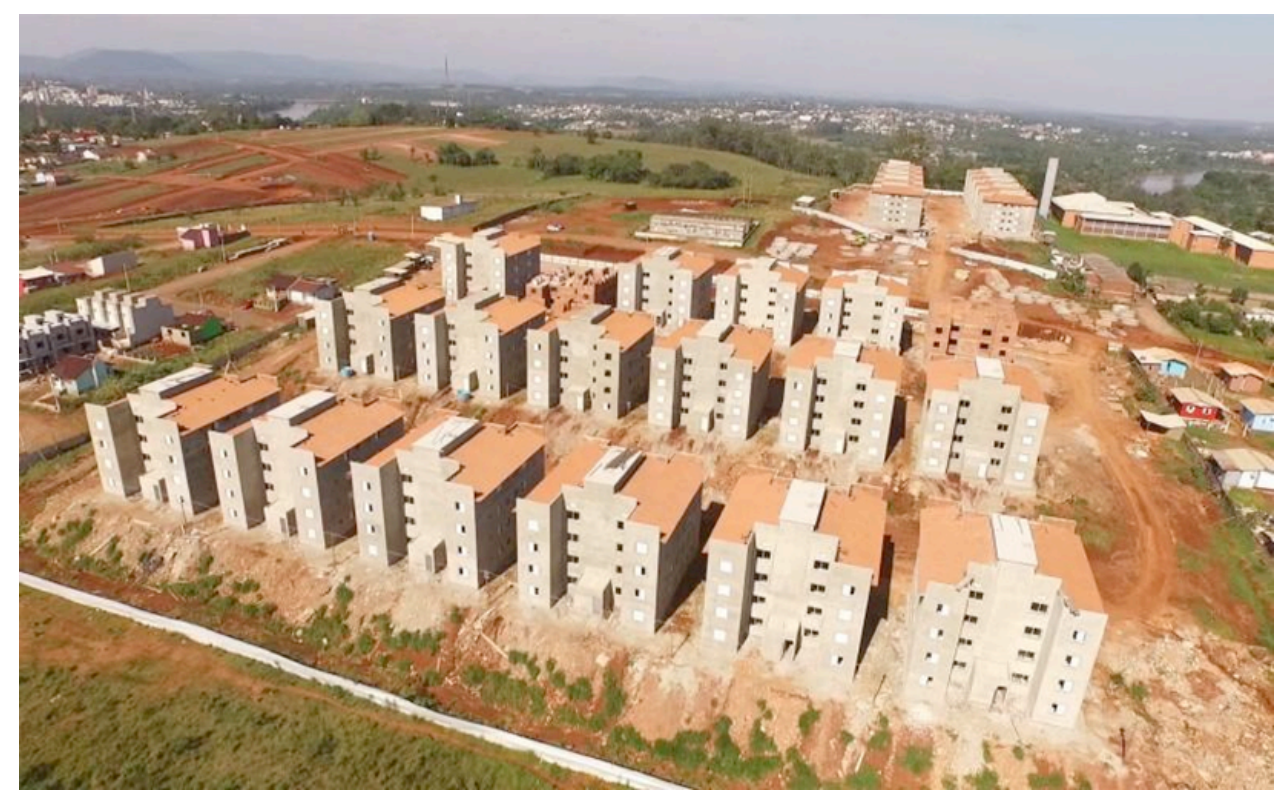

Fonte: Novo (2016).

Fig. No 9: Obras de infraestruturas no bairro

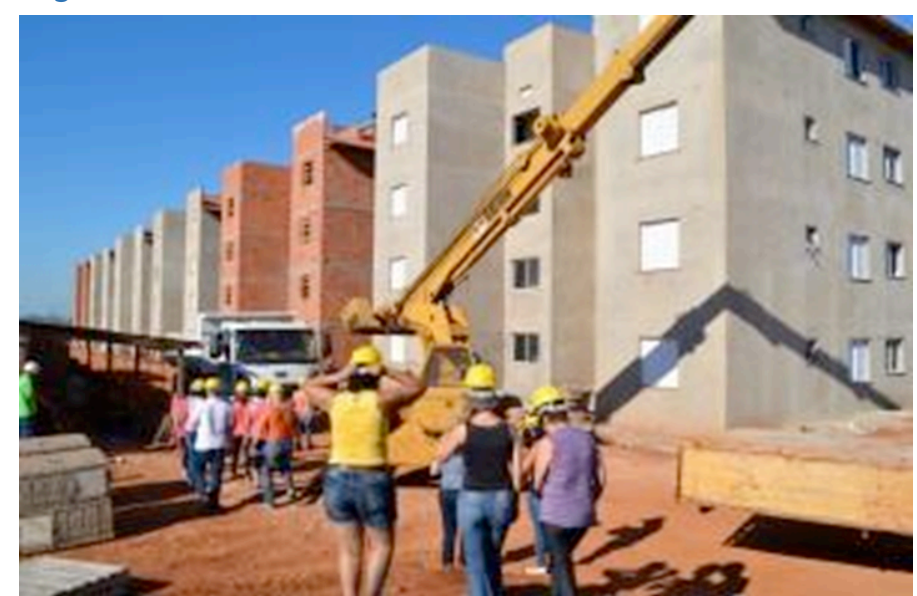

Fonte: Novo (2016). Jornal A Hora. 12/02/2016

A Figura 8 apresenta uma vista aérea dos conjuntos habitacionais Novo Tempo I e II, o 
maior empreendimento social da história da cidade de Lajeado. Esse tipo de perspectiva aérea com ponto de vista oblíquo, muito utilizado pelos arquitetos modernistas, oferece uma aparente legibilidade do projeto para um público leigo. Essa narrativa visual das realizações do PMCMV procura mostrar a força construtora, a potência e o controle do estado. Na Figura 9, as obras de pavimentação e infraestrutura sendo vistoriadas por funcionários do município ilustram a ação do município no desenvolvimento dos bairros, a força construtora do Poder Municipal além das casas trará melhorias no bairro. O jornal O Informativo do Vale cita o empreendedor e diretor da construtora ALM, responsável pela realização dos 28 prédios, totalizando 458 apartamentos que ressalta a importância da obra social que deverá beneficiar mais de duas mil pessoas que vivem hoje em situação de vulnerabilidade: "O bairro vai melhorar. Quem vai prosperar é a comunidade que vai ganhar um novo, um novo tempo!".

\section{CONSIDERAÇÕES FINAIS}

A construção do imaginário ligado ao Programa Minha Casa Minha Vida é fruto de relações e poderes e seus discursos elaborados através das representações urbanas. A série de imagens apresentadas neste trabalho tenta captar um olhar da sociedade brasileira contemporânea sobre a habitação de interesse social. Através das representações ligadas à construção do maior conjunto habitacional do Programa Minha Casa Minha Vida na história da cidade de Lajeado, uma cidade de médio porte no Rio Grande do Sul, o trabalho se propôs a mostrar a relação de segregação que se estabelece na sociedade entre as camadas mais abastadas e aquelas de rendimentos modestos, o que causa divisões notáveis e profundas (VILLAÇA, 1998). As construções discursivas elaboradas por essas imagens e textos definiram um determinado lugar social tanto dos atores institucionais quanto dos sujeitos "beneficiados" pelo programa e colocam em relevo os mecanismos operados localmente pelo poder público para consolidar e justificar a ação de um Estado caritativo.

\section{REFERÊNCIAS}

APARTAMENTOS do residencial Novo Tempo II são entregues a moradores. Portal Região dos Vales, 16 mar. 2017. Disponível em: http://www.regiaodosvales.com.br/apartamentos-doresidencial-novo-tempo-ii-sao-entregues-a-moradores/. Acesso em: 19 jun. 2017.

BARTHES, Roland. Rhétorique de l'image. Communications, v. 4, n.1, p. 40-51, 1964.

BONDUKI, Nabil. Origens da habitação social no Brasil: arquitetura moderna, lei do inquilinato e difusão da casa própria. São Paulo: Estação Liberdade, 1998.

BONTE, P; IZARD, M. Dictionnaire de l'ethnologie et de l'anthropologie. Paris: P.U.F., 1991. 
BOURDIEU, Pierre. Langage et pouvoir symbolique. Paris: Points, 2002.

BURKE, Peter. Eyewitnessing: the use of images as historical evidence. London: Reaktion books, 2004.

CARDOSO, A. L; ARAGAO, T.A.; JAENISCH, S. T (org.). Vinte e dois anos de política habitacional no Brasil: da euforia à crise. Rio de Janeiro: Letra Capital. Observatório da Metrópoles, 2017.

CASA própria chega para 160 famílias. Jornal A Hora, 15 mar. 2017. Disponível em: http://www.jornalahora.com.br/2017/03/15/casa-propria-chega-para-160-familias/. Acesso em: 19 jun. 2017.

FOUCAULT, Michel. L'ordre du discours. Paris: Gallimard, 1971.

HALL, Stuart. (Ed.) Representation: cultural representations and signifying practices. London: Sage, 1997.

MARIN, Louis. Politiques de la représentation. Paris: Kimé, 2005.

MINHA casa minha vida. 2017. Disponível em: <http://www.minhavidaminhacasa.com>. Acesso em: 19 jun. 2017.

NOVO Tempo alcança 75\% de conclusão. Jornal A Hora, 12 fev. 2016. http://www.jornalahora.com.br/2016/02/12/novo-tempo-alcanca-75-de-conclusao/. Acesso em: 19 jun. 2017.

OLSON, David. Richard. 0 mundo no papel: as implicações conceituais e cognitivas da leitura e da escrita. São Paulo: Ática, 1997.

PESAVENTO, Sandra. Jatahi. et al. (Org.) Narrativas, imagens e práticas sociais: percursos em história cultural. Porto Alegre: Asterisco, 2008.

PRESSER, Thais. Moradores escolhem apartamentos no Novo Tempo. Jornal 0 Informativo do Vale, 13 jan. 2017. Disponível em: https://www.informativo.com.br/geral/moradores-escolhemapartamentos-no-novo-tempo,39881.jhtml. Acesso em: 19 jun. 2017.

ROLNIK, R. et al. 0 programa Minha Casa Minha Vida nas regiões metropolitanas de São Paulo e Campinas: aspectos sócio espaciais e segregação. Cad. Metrop., São Paulo, v. 17, n.33, pp. 127-154, mai 2015. Disponivel em:<http://dx.doi.org/10.1590/2236-9996.2015-3306 >. Acesso em 02 abr. 2017.

SILVA, M.; TOURINHO, H. 0 banco Nacional de Habitaçao e o Minha Casa Minha Vida: duas politicas habitacionais e uma mesma logica locacional. Cad. Metrop., Sao Paulo, v.17, n.34, p. 401-417, nov. 2015; Disponivel em: <http://www.scielo.br/pdf/cm/v17n34/2236-9996-cm-1734-0401.pdf>. Acesso em: 03 mar. 2017. 
SORTEIO define 448 famílias moradoras do condomínio Novo Tempo. Jornal 0 Informativo do Vale, 28 jun. 2015. Disponível em: <https://www.informativo.com.br/geral/sorteio-define-448-familiasmoradoras-do-condominio-novo-tempo,29758.jhtml>. Acesso em: 19 jun. 2017.

VILLAÇA, Flavio. Espaço intra-urbano no Brasil. São Paulo: Studio Nobel, 1998.

Recebido em 04 de maio de 2018.

Aprovado em 06 de dezembro de 2018. 